\title{
SEYED HOSSEIN IRADJ MOEINI, MEHRAN AREFIAN, BA- HADOR KASHANI E GOLNAR ABBASI : FeUrban Culture in Tehran: Urban Processes in Unofficial Cultural Spaces)
}

Nuestras ciudades no son elementos estáticos, ya que siempre están sufriendo cambios constantes debido al uso de los espacios urbanos por parte de sus habitantes. Siguiendo las directrices definidas por los regímenes centrales y locales, a través de la planificación urbana, se deben utilizar ciertos espacios urbanos tal como se definen en estos planes. Pero, ¿y si los espacios urbanos se utilizaran de forma alternativa a la definida por los planificadores urbanos? Este es el objetivo principal del libro "Urban Culture in Tehran: Urban Processes in Unofficial Cultural Spaces" de Seyed Hossein Iradj Moeini, Mehran Arefian, Bahador Kashani y Golnar Abbasi. Con este libro, los autores pretenden mostrar usos alternativos del espacio urbano, desafiando las tradiciones islámicas en la capital de Irán, Teherán. Con un breve resumen del libro, a continuación se presenta una crítica del mismo.

En el capítulo 1 ( «Poder y Resistencia: Dualidad Eterna») y teniendo en cuenta que el espacio urbano es un espacio social que es constantemente disputado y apropiado por diferentes grupos sociales, Teherán, capital de Irán, no es una excepción. Existe claramente un conflicto constante entre los discursos oficiales del régimen que definen el uso que debe hacerse de los distintos espacios urbanos (más tradicionales) y entre los distintos discursos sobre los usos que los grupos sociales desfavorecidos, nacidos de callejones y barrios, hacen de estos mismos espacios (más alternativos). Este es el objetivo de este libro: entender cómo estos discursos sobre el uso alternativo del espacio emergen y permanecen en esta ciudad, hablando de algunos espacios alternativos en particular, como cafés, librerías y galerías.

En el capítulo 2 ( «Los rituales de la bebida y la semántica de la cultura alternativa: los cafés de Teherán»), los autores hablan de la aparición de los «cafés», inspirados en los cafés franceses del siglo XIX, donde varias personas se reúnen en estos espacios, no para consumir café, sino para otras actividades sociales: hablar, trabajar, asistir a un concierto, ver eventos deportivos en televisión o leer un libro. Al no tener grandes carteles y no ser fáciles de identificar su ubicación, estos espacios, con una decoración occidental, desafían los discursos tradicionales del régimen que no permiten este tipo de espacios. Un espacio alternativo donde la gente, especialmente los jóvenes y los adultos altamente cualificados, pueden escapar de las tradiciones impuestas por el régimen.

En el capítulo inmediato ( $«$ A Multifaceted Reading Culture: Tehran Alternative Booksellers and the Mainstream»), también con respecto al consumo de cul- 
tura, a saber, editores y librerías, existe una dicotomía: por una parte, una red de editores y librerías que cuentan con el apoyo del régimen, ya que comercializan libros vinculados a la religión y la cultura islámica y, por otra, una red alternativa de editores y librerías, que venden libros que, en la mayoría de los casos, no están permitidos por el régimen. Caracterizados por una decoración alternativa o incluso por la venta callejera, sus comerciantes venden los libros que las personas detenidas no pueden comprar.

En el capítulo 4 («Una genealogía de las galerías de arte de Teherán: una historia del estudio (casero)»), y como en los capítulos anteriores sobre galerías de arte, vemos una resistencia a la ideología del régimen, creando espacios alternativos a los del régimen. Aprovechando su propiedad privada, muchos de los artistas se refirieron a crear estudios de arte y galerías $\mathrm{y}$, sin mucha publicidad externa, exhiben sus obras artísticas a sus visitantes, contrariamente a lo que ocurre con el régimen.

Finalmente, en el último capítulo («Reflexiones finales: anacronismos, cuestiones siempre presentes y especificidades»), los autores llaman la atención sobre el hecho de que vivimos en un mundo en el que toda apropiación del espacio urbano con fines culturales sigue las ideologías del régimen y los fines económicos, pero se preguntan si estas alternativas presentadas aquí no pueden normalizarse, haciéndolas no alternativas y únicas, sino banales y comunes. Con esta breve presentación del libro, es posible hacer una evaluación crítica del mismo y reflexionar sobre lo que este libro puede aportar de relevante para el conocimiento científico, es decir, para la Sociología.

En primer lugar, debemos pensar en el contexto en el que se llevó a cabo esta investigación, a saber, la capital del país que es objeto de análisis: Teherán, capital de Irán. Esta es la capital de un país islámico, en el que la religión islámica tiene una gran importancia y, por lo tanto, las tradiciones relacionadas con esta religión están muy presentes y no pueden ser contradichas. Esto es tan importante que el propio régimen iraní tiene fuerzas de seguridad dispuestas a arrestar a cualquiera que contradiga las tradiciones o cuestione las ideas vinculadas al régimen. Pero como en otros regímenes autoritarios, no todos sus habitantes están de acuerdo con las ideas del régimen. En esta línea de pensamiento, se crean discursos alternativos a los transmitidos por el régimen por sus oponentes. El caso de Teherán que se nos presenta aquí no es una excepción.

Más que pensar en la oposición al régimen que quiere derrocarlo, entendemos que esta oposición presentada aquí crea discursos alternativos sobre lo que debería ser la producción y el consumo de cultura en este país. Más que la producción y el consumo de la cultura oficial del régimen, la gente está buscando una cultura alternativa, a saber, la cultura occidental. Para la producción y el consumo de esta cultura se necesitan espacios alternativos a los espacios convencionales, fieles al régimen y donde se presenten las tendencias más recientes asociadas a la cultura iraní e islámica.

Son estos mismos espacios alternativos los que centran nuestra atención a lo largo de este libro y es aquí donde los autores de este libro son originales, mostrándonos cómo estos espacios urbanos, diferentes de los espacios convencionales y siguiendo las tradiciones del régimen iraní, consiguen ser alternativos. Los autores, con los ejemplos ilustrados anteriormente, nos muestran la aplicación del concepto de Henri Lefebvre, el «derecho a la ciudad», aplicado en nuestra contemporaneidad, aunque este concepto fue creado en 1968. En otras palabras, todos tenemos derecho a disfrutar de los espacios urbanos de nuestras ciudades, a satisfacer necesidades o a conquistar 
derechos, como el derecho a la salud, a la educación, pero en este caso particular, el derecho a una cultura alternativa. Una cultura diferente a los discursos oficiales del régimen y que permite la absorción de un conocimiento alternativo, a menudo oculto por el régimen.

No queriendo resignarse a los espacios oficiales e incluso conociendo las represalias que podrían sufrir, estas personas crean espacios alternativos donde la gente puede consumir una cultura alternativa, a saber, la cultura occidental. $\mathrm{La}$ mayoría de estos espacios son difíciles de encontrar y con poca publicidad externa, pero la gente es consciente de que a pesar de vivir en un régimen autoritario, tienen derecho a disfrutar de los espacios urbanos de su ciudad, con el fin de satisfacer sus necesidades y ganar derechos. Estas personas aplican, inconscientemente, el concepto de Lefebvre, en la creación y mantenimiento de estos espacios alternativos.

Lo que encontramos en este libro, por tanto, es una aplicación del concepto de Henri Lefebvre en ciudades fuera del mundo occidental, que encaja perfectamente en el caso de la ciudad de Teherán, Irán, mostrando así cómo se aplica este concepto en una ciudad regida por tradiciones islámicas, pero sobre todo muestra la aplicación de este concepto a la emergencia del uso del espacio urbano para la creación de espacios alternativos a los convencionales.

Más que un ejemplo de una aplicación de Henri Lefebvre, este libro plantea dos puntos que es importante destacar: El primer punto es que el concepto de Lefebvre puede aplicarse en ciudades fuera del mundo occidental, como se puede ver, pero el segundo punto es aún más relevante, es decir, que el concepto de Lefebvre puede ser aplicado por todos aquellos que deseen justificar el uso alternativo de los espacios urbanos a los acordados por la planificación urbana, incluso en regímenes autoritarios, como el régimen ayatolá en Irán.

Este es un libro muy interesante, con muchas fotografías que ilustran los ejemplos que se están describiendo a lo largo de él y lo más interesante de todo, es que los autores nunca se refieren a este concepto de Henri Lefebvre, aunque su presencia está implícita. Este libro nos permite echar un vistazo, a través de un ejemplo de Oriente Medio, a cómo pueden ser las ciudades fuera del mundo occidental. Porque más que conocer el fenómeno de la urbanización de las ciudades occidentales, es necesario salir de ese mundo occidental para conocer el mismo fenómeno, pero aplicado a ciudades de otros rincones del mundo, ya sea en África, América Latina o Asia.

La visión que presenta este libro nos ayuda a inaugurar nuevas líneas de investigación en Sociología Urbana, pero también muestra que, incluso en los regímenes autoritarios, hay signos de resistencia y oposición a ella, aunque sólo sea a través de la reivindicación de un derecho tan simple como es nuestro derecho a disfrutar de los espacios públicos urbanos para hacer lo que queramos. Este libro da pistas para futuras investigaciones, que pueden incluso motivar a quienes lean este libro a continuar investigando en este campo. 
Resumen: Ya sea que estemos sentados en un banco de parque o ocupando una calle con una manifestación, tenemos una apropiación constante del espacio urbano, en cualquier parte de la ciudad. Aún así, existe un claro intento de definir qué uso se debe hacer del espacio urbano que se concibió y creó. Pero, ¿qué ocurre con los discursos alternativos a los discursos establecidos por el régimen, incluso en los regímenes autoritarios? Esta es la discusión llevada a cabo por un grupo de autores que hablan del caso de Teherán, la capital de Irán, en el que muestran que a pesar de los discursos del régimen, siempre hay discursos alternativos a los que transmite el Estado. Se hace una breve síntesis de las ideas de este libro, y luego se complementa con una crítica del mismo.
Abstract: Whether we are sitting on a park bench or occupying a street with a demonstration, we have a constant appropriation of urban space, anywhere in the city. Even so, there is a clear attempt to define what use should be made of the urban space that was conceived and created. But what about alternative discourses to the discourses established by the regime, even in authoritarian regimes? This is the discussion carried out by a group of authors who speak of the case of Teheran, the capital of Iran, in which they show that in spite of the speeches of the regime, there are always alternative speeches to those transmitted by the State. A brief synthesis of the ideas of this book is made, and then complemented with a critique of it.

Pedro Saraiva

Universidad de Coimbra (FEUC) 